\title{
AGREGAÇÃO DE UM LATOSSOLO VERMELHO SUBMETIDO A CINCO SISTEMAS DE PREPARO DO SOLO EM UBERABA - MG
}

\section{ALBERTO CARVALHO FILHO ${ }^{2}$, ROUVERSON P. DA SILVA ${ }^{3}$, JOSÉ F. CENTURION ${ }^{4}$, LUÍS C. C. CARVALHO ${ }^{5}$, AFONSO LOPES}

RESUMO: Visando à obtenção de dados relativos aos efeitos de sistemas de preparo periódico do solo e sua relação com a degradação do solo e a capacidade de incorporação de resíduos, avaliaram-se a distribuição percentual de agregados do solo, o diâmetro médio geométrico, o módulo de finura e a incorporação de resíduos, durante o ano agrícola de 2001-2002. A área em estudo foi classificada como Latossolo Vermelho distrófico, localizada no município de Uberaba MG. Utilizou-se do delineamento estatístico em blocos casualizados com quatro repetições, tendo como tratamentos o preparo periódico primário do solo com o escarificador, enxada rotativa, arado de aivecas, grade aradora e arado de discos. As análises dos resultados mostraram a enxada rotativa e a grade aradora como os equipamentos mais agressivos à estrutura do solo. $\mathrm{O}$ escarificador e a enxada rotativa apresentaram menor capacidade de incorporação dos resíduos vegetais. $\mathrm{O}$ escarificador manteve maior cobertura vegetal e maior grau de agregação do solo.

PALAVRAS-CHAVE: cobertura vegetal, diâmetro médio geométrico, distribuição de agregados do solo.

\section{AGGREGATION OF AN HAPLUSTOX UNDER FIVE SYSTEMS SOIL TILLAGE IN UBERABA, STATE OF MINAS GERAIS, BRAZIL}

\begin{abstract}
Trying to obtain information on the effects of systems of soil tillage and its relationship with the degradation of the soil and the capacity of incorporation of residues, percentages of distribution of soil aggregates, the geometric mean diameter, thinness' module and incorporation of residues were evaluated in 2001/2002. The soil of the areas was classified as Haplustox, in Uberaba's district situated in Minas Gerais, Brazil. The experimental randomized blocks design was used, in a split plot scheme, with four replications. The treatments were the soil tillage with chisel plow, rotary hoe, moldboard plow, disk harrow and disk plow, and four repetitions. The analyses of the results showed the rotary hoe and the disk harrow as the most aggressive equipments to the structure of the soil. The chisel plow and the rotary hoe presented smaller capacity of incorporation of the vegetable residues. The chisel plow kept greater vegetable covering and larger degree of soil aggregation.
\end{abstract}

KEYWORDS: residues incorporation, geometric mean diameter, distribution of the soil aggregates.

\section{INTRODUÇÃO}

O preparo periódico do solo tem como finalidades a mobilização, o destorroamento, o controle de plantas daninhas, a incorporação de restos vegetais, de corretivos e de defensivos agrícolas, proporcionando, assim, condições favoráveis para a semeadura, cultivo, adubação e também uma compactação desejável para o desenvolvimento radicular das plantas (DICKEY et al., 1992).

\footnotetext{
${ }^{1}$ Extraído da Tese de Doutorado do primeiro autor.

${ }^{2}$ Prof. Dr., FAZU, Uberaba - MG e FAFRAM, Ituverava - SP, alberto@ fazu.br

${ }^{3}$ Prof. Dr., Departamento de Engenharia Rural, UNESP, Jaboticabal - SP.

${ }^{4}$ Prof. Adjunto, Departamento de Solos e Adubos, UNESP, Jaboticabal - SP.

${ }^{5}$ Graduando em Agronomia, UFLA, Lavras - MG.

${ }^{6}$ Prof. Adjunto, Departamento de Engenharia Rural, UNESP, Jaboticabal - SP.

Recebido pelo Conselho Editorial em: 13-12-2005

Aprovado pelo Conselho Editorial em: 8-2-2007
} 
De acordo com MAZUCHOWSKI \& DERPSCH (1984), denomina-se preparo periódico às operações de movimentação do solo, com a finalidade de instalação periódica de culturas e, de forma geral, pode-se dividi-lo em:

1 - Preparo primário do solo (aração e/ou escarificação): são operações mais profundas e grosseiras que têm como objetivo o revolvimento do solo, promovendo ou não a incorporação da vegetação instalada e dos restos de cultura; geralmente deixam a superfície do terreno irregular, com torrões e desnivelada, dificultando as operações seguintes de plantio e cultivo. Recomenda-se que nesse preparo não ocorra excessiva quebra dos torrões, deixando o máximo possível de resíduos vegetais na superfície, atingindo profundidade suficiente para permitir boa infiltração de água no solo e menor risco de erosão, e

2 - Preparo secundário do solo (destorroamento e nivelamento): pode ser definido como todas as operações superficiais realizadas após o preparo primário, visando ao nivelamento do terreno, ao destorroamento, à incorporação de herbicidas, à eliminação de plantas invasoras no início do seu desenvolvimento, ou a permitir a fácil colocação da semente no solo e sua cobertura com terra, produzindo ambiente favorável ao desenvolvimento inicial da cultura, com reflexos diretos na produção. Todas as atividades de preparo secundário do solo (gradagens em geral) deverão ser feitas com o mínimo de operações possível, evitando a ação pulverizadora das grades e a compactação do solo solto com o pneu do trator e com os equipamentos.

A intensificação do emprego de máquinas em tarefas agrícolas concorre para a expansão da degradação dos solos por torná-los mais desestruturados e sem cobertura vegetal por maior período (DIAS, 1993).

O preparo intensivo induz a formação de uma camada compactada, subsuperficialmente no solo, reduzindo a permeabilidade e a profundidade efetiva, favorecendo o aumento do carreamento da massa de terra, pela lavagem superficial do terreno, com sérios prejuízos para a produtividade das culturas (MORAES \& BENEZ, 1996).

Adequar solos, deixando-os em condições ideais para o desenvolvimento das culturas, implica melhorar e manter sua estrutura, com espaço poroso satisfatório, fazendo com que a disponibilidade de água e a troca de gases e nutrientes sejam suficientes para o desenvolvimento das plantas. Porém, mantê-los em condições ideais é extremamente difícil, pois as próprias atividades relacionadas com a produção agrícola deterioram a estrutura do solo, limitando o desenvolvimento das raízes pela compactação do solo (LOPES, 2002). A maioria das características físicas do solo sofre variações cíclicas a cada instalação de culturas, alterando-se de um preparo periódico a outro subseqüente.

O diâmetro médio geométrico e o módulo de finura dos agregados do solo permitem avaliar as condições da camada mobilizada quanto ao seu estado de desagregação, o qual se revela da maior importância quanto às condições do solo para execução da semeadura (COAN, 1995). No trabalho desenvolvido por esse autor, foi verificada que, após a realização do preparo periódico secundário do solo, formaram-se agregados de tamanhos semelhantes e que o aumento do número de operações de uma grade niveladora não alterou o tamanho de agregados.

GROHMANN \& ARRUDA (1961) recomendam a menor mobilização possível do solo, visando a preservar sua estrutura, visto que o preparo intensivo diminui o diâmetro médio geométrico dos agregados. Assim, quanto menor o número de operações mecanizadas para a exploração agrícola, maiores serão os benefícios à sustentabilidade ambiental e, frequientemente, mais econômicas serão essas operações (LEVIEN et al., 2003).

De acordo com SALVADOR et al. (1993), COAN (1995) e LOPES (2002), a mobilização do solo e a proteção do mesmo com resíduos vegetais são essenciais para a obtenção e a manutenção de boas produtividades das culturas anuais.

De acordo com BUHLER (1995), deve-se manter, no mínimo, 30\% da superfície do solo coberta com palha, entre o período compreendido da colheita da cultura anterior e a implantação da 
cultura seguinte, pois considera-se a cobertura do solo por resíduos a principal característica do preparo conservacionista.

O presente trabalho foi realizado com o objetivo de avaliar os efeitos de sistemas de preparo periódico do solo sobre o estado de agregação de um Latossolo Vermelho distrófico e na capacidade de incorporação de resíduos pelos equipamentos agrícolas.

\section{DESCRIÇÃO DO ASSUNTO}

O experimento foi instalado e conduzido no município de Uberaba - MG, em um Latossolo Vermelho distrófico, textura média, relevo plano e densidade média na camada arável igual a $1,73 \mathrm{~kg} \mathrm{dm}^{-3}$, localizado em área com as seguintes coordenadas geográficas: longitude $47^{\circ} 57^{\prime} \mathrm{W}$, latitude $19^{\circ} 44^{\prime} \mathrm{S}$, e altitude de $780 \mathrm{~m}$.

O clima de Uberaba, segundo a classificação de Köeppen, é do tipo Aw, tropical quente úmido, com inverno frio e seco. As médias anuais de precipitação e temperatura são de $1.474 \mathrm{~mm}$ e $22,6^{\circ} \mathrm{C}$, respectivamente.

O delineamento estatístico utilizado foi em blocos casualizados, com cinco tratamentos e quatro repetições, resultando num total de 20 parcelas, tendo como tratamentos o preparo periódico primário com escarificador equipado com cinco hastes, desprovido de rolo destorroador; enxada rotativa equipada com seis flanges, tendo quatro lâminas tipo veloz por flange, com rotação média de $210 \mathrm{rpm}$ e anteparo traseiro levantado; arado de aivecas fixas, equipado com duas aivecas recortadas; grade aradora de arrasto, equipada com 14 discos recortados de 609,6 mm (24") x $6,0 \mathrm{~mm}$, e arado de discos fixos, equipado com quatro discos de 660,4 mm (26") x 4,7 mm. Cada parcela constituiu-se de $100 \mathrm{~m}^{2}$ (10 x $\left.10 \mathrm{~m}\right)$.

Utilizou-se do trator Ford $6610,4 \times 2$, com potência de $62,5 \mathrm{~kW}(85 \mathrm{cv})$, operando em velocidade média de $5 \mathrm{~km} \mathrm{~h}^{-1}$, na tração dos arados, do escarificador e da grade, e um trator Agrale $4100,4 \times 2$, com potência de 10,8 kW (14,7 cv), e velocidade média de operação igual a $1,5 \mathrm{~km} \mathrm{~h}^{-1}$, para tracionar a enxada rotativa. Os dois tratores utilizados trabalharam com equipamentos dimensionados para as suas respectivas potências e na velocidade média recomendada para cada operação, conforme manual dos fabricantes.

Os arados de discos e de aivecas e o escarificador foram regulados para cortarem o solo numa profundidade média de $20 \mathrm{~cm}$, a grade aradora a $13 \mathrm{~cm}$ e a enxada rotativa a $8 \mathrm{~cm}$. Foi utilizado o preparo convencional para os arados e para a grade aradora, sendo realizada a primeira gradagem de nivelamento logo após o preparo periódico primário, e a segunda antecedendo a semeadura. Para o escarificador, utilizou-se do preparo reduzido do solo, sendo realizada apenas uma gradagem de nivelamento, antecedendo a semeadura, enquanto para a enxada rotativa o solo não sofreu nova mobilização. A umidade gravimétrica do solo no momento do preparo foi de $16 \%$.

Logo após a execução de cada tratamento, conforme a profundidade de solo mobilizada, foi utilizada uma armação quadrada, de ferro, com dimensões laterais internas de $300 \mathrm{~mm}$, para a demarcação da área de coleta. Após a retirada do solo das laterais externas dessa armação, coletaram-se, com auxílio de uma pá, no centro de cada parcela, três subamostras que foram acondicionadas em caixas de papelão. No laboratório, essas amostras foram secas ao ar, com o objetivo de reduzir a água existente no solo e de conferir a resistência mecânica dos agregados para a operação de peneiramento manual, a seco. Após terem sua umidade reduzida, as amostras foram passadas separadamente em peneiras para a obtenção da massa seca dos agregados por classe de tamanho. Tomou-se a média dos valores de três subamostras como a amostra da parcela.

A agregação do solo na camada mobilizada foi avaliada por meio dos cálculos do diâmetro médio geométrico dos agregados (DMG), obtida por meio da eq.(1), tomando-se como referência o trabalho de GUPTA \& LARSON (1982). O módulo de finura (MF), determinado pela eq.(2), e a percentagem de agregados retidos por classe de tamanho (Wi), conforme eq. (3), ou seja: maiores que 50,$80 ; 50,80$ a 38,$10 ; 38,10$ a 25,$40 ; 25,40$ a 19,$00 ; 19,00$ a 12,$70 ; 12,70$ a 9,$52 ; 9,52$ a 4,75 ; 
4,75 a 2,36; 2,36 a 1,$19 ; 1,19$ a 0,$59 ; 0,59$ a 0,$30 ; 0,30$ a 0,15 e menores que $0,15 \mathrm{~mm}$. A escolha das classes de tamanho deu-se em função da abertura de malhas do jogo de peneiras (GAMERO, 1989).

$$
\begin{aligned}
& \mathrm{DMG}=\operatorname{antilog}\left[\frac{\sum_{\mathrm{i}=1}^{\mathrm{n}}(\mathrm{Wilogdi})}{\sum_{\mathrm{i}=1}^{\mathrm{n}} \mathrm{Wi}}\right] \\
& \mathrm{MF}=\frac{\sum \text { percentagens acumuladas }}{100} \\
& \mathrm{Wi}(\%)=\frac{\mathrm{Wi}}{\sum_{\mathrm{i}=1}^{\mathrm{n}} \mathrm{Wi}} 100
\end{aligned}
$$

em que,

$\mathrm{Wi}$ - massa retida por classe de tamanho, g;

MF - módulo de finura;

di - tamanho médio da classe, $\mathrm{mm}$;

n - número de classe de agregados, e

DMG - diâmetro médio geométrico, mm.

Por meio do levantamento efetuado na superfície do solo, verificou-se a predominância de plantas daninhas de porte rasteiro e restos de cultura de milho, que foram roçados para evitar o embuchamento durante as fases de preparo do solo.

A avaliação da quantidade de resíduos foi realizada antes e após o preparo primário, e após o preparo secundário do solo, utilizando-se de uma trena, que foi colocada sobre a superfície de cada parcela, em posição diagonal, tomando-se leituras em 100 marcas, distanciadas de $10 \mathrm{~cm}$ entre si. $\mathrm{O}$ percentual de cobertura foi avaliado considerando-se a coincidência de cada marca sobre os resíduos, conforme adaptação do método de LAFLEN et al. (1981).

Os dados obtidos foram submetidos à análise de variância e quando as diferenças encontradas entre os tratamentos foram significativas, aplicou-se o teste de comparação de médias de Tukey $(\mathrm{p} \leq 0,05)$.

\section{Percentagem de agregados no solo}

$\mathrm{Na}$ Tabela 1, são apresentados os resultados da distribuição percentual média de agregados no solo retidos nas diferentes classes, conforme o equipamento de preparo do solo.

TABELA 1. Percentagem média de agregados no solo (\%), por classe de tamanho, em função do sistema de preparo periódico do solo.

\begin{tabular}{lcccccc}
\hline \multirow{2}{*}{ Classes (mm) } & \multicolumn{5}{c}{ Sistemas } \\
\cline { 3 - 7 } & Escarificador & Enxada Rotativa & Arado de Aivecas & Grade Aradora & Arado de Discos \\
\hline 1 & $>50,80$ & 21,9 & 0,0 & 26,5 & 8,1 & 6,5 \\
2 & 38,10 a 50,80 & 3,6 & 1,1 & 2,8 & 2,3 & 7,8 \\
3 & 25,40 a 38,10 & 6,6 & 0,3 & 6,5 & 4,2 & 8,9 \\
4 & 19,00 a 25,40 & 5,2 & 4,1 & 4,0 & 6,8 & 8,7 \\
5 & 12,70 a 19,00 & 4,7 & 2,8 & 5,3 & 4,6 & 7,1 \\
6 & 9,52 a 12,70 & 3,2 & 4,6 & 2,5 & 3,5 & 4,3 \\
7 & 4,75 a 9,52 & 11,9 & 18,5 & 10,9 & 11,8 & 13,0 \\
8 & 2,36 a 4,75 & 6,7 & 11,4 & 6,4 & 8,5 & 7,4 \\
9 & 1,19 a 2,36 & 13,5 & 26,1 & 10,5 & 15,8 & 13,8 \\
10 & 0,59 a 1,19 & 12,1 & 19,6 & 15,6 & 22,2 & 13,7 \\
11 & 0,30 a 0,59 & 7,9 & 8,9 & 6,8 & 8,8 & 6,5 \\
12 & 0,15 a 0,30 & 2,2 & 2,2 & 1,7 & 2,7 & 1,8 \\
13 & $<0,15$ & 0,7 & 0,5 & 0,5 & 0,9 & 0,5 \\
\hline
\end{tabular}


A análise dos resultados permite observar que a percentagem de agregados nas classes de maior tamanho (classes 1; 2 e 3) se encontra nos preparos de solo com os arados de aivecas, escarificador e arado de discos, destacando-se a similaridade de valores ocorrida entre os dois primeiros. Para o arado de discos, houve maior uniformidade de tamanho de agregados entre todas as classes tomadas (Figura 1).

Verifica-se, também, que a enxada rotativa se revelou como um equipamento de significativa capacidade desagregante, não produzindo torrões na classe 1, na qual os agregados possuem tamanhos maiores que $50,8 \mathrm{~mm}$, e com mínimas percentagens até a classe 3 , prevalecendo, portanto, os agregados com dimensões menores que $25,4 \mathrm{~mm}$. De modo similar, a grade aradora mostrou sua grande capacidade de pulverização do solo, apresentando apenas 14,6\% dos agregados com dimensões compreendidas entre as classes 1 e 3 , proporcionando, assim, também o predomínio de agregados menores que $25,4 \mathrm{~mm}$.

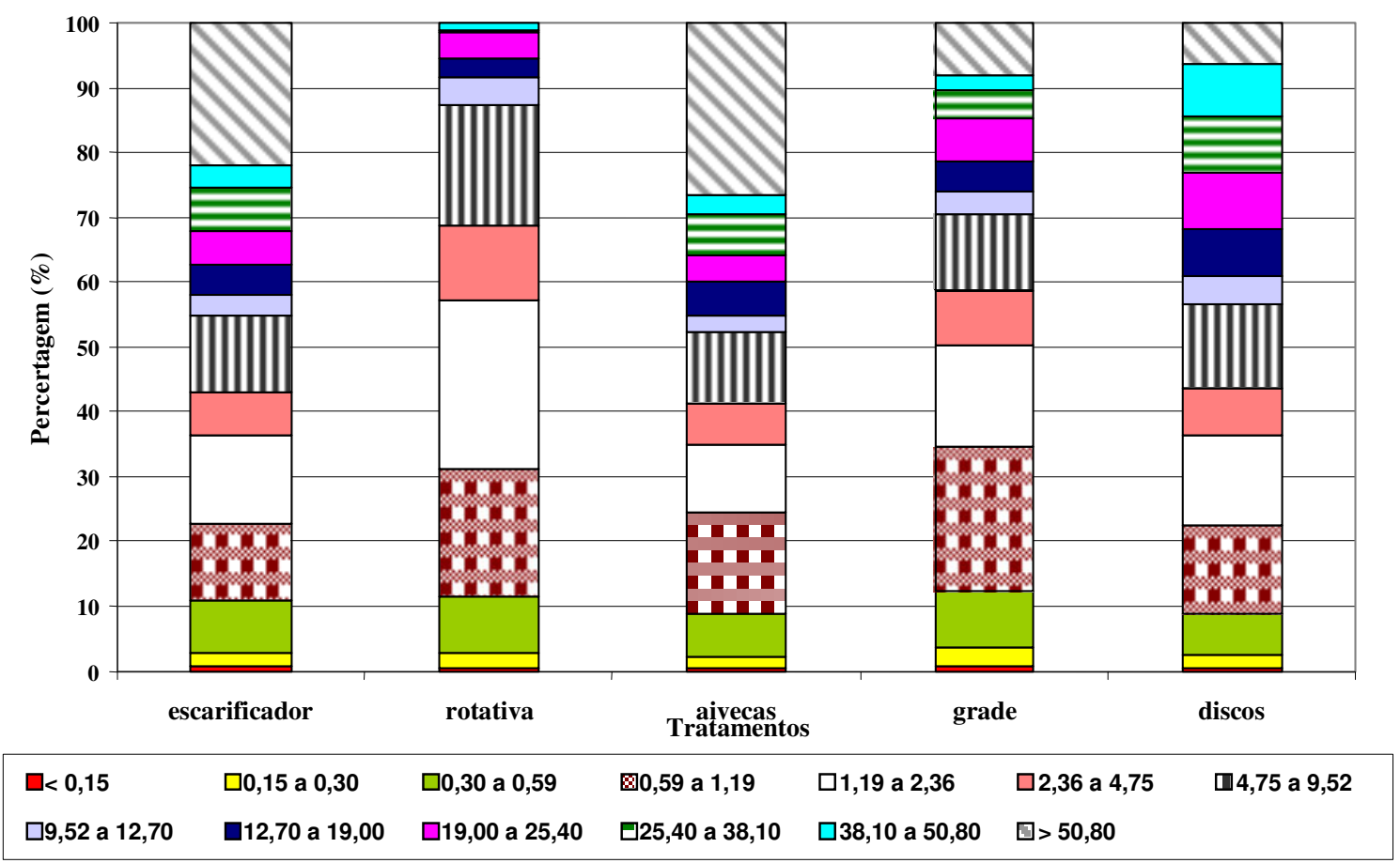

FIGURA 1. Distribuição percentual de agregados por classe de tamanho (mm), em função do sistema de preparo periódico do solo.

Por meio da Figura 2, pode-se observar que os agregados referentes às classes 1 e 2 correspondem a $29,3 \%$ e $25,4 \%$ para o arado de aivecas e escarificador, respectivamente, representando que aproximadamente $70 \%$ de agregados possuem dimensões inferiores a $38,1 \mathrm{~mm}$, enquanto percentuais semelhantes são encontrados entre as classes 7 a $13(68,7 \%)$ para a enxada rotativa e 6 a $13(70,6 \%)$ para a grade aradora, mostrando o efeito mais agressivo desses equipamentos à estrutura do solo.

Pelos resultados da enxada rotativa e da grade aradora, também se verifica maior percentual de agregados menores que 4,75 mm, com 57,3 e 50,3\%, respectivamente, comparados aos demais equipamentos, com aproximadamente $35 \%$ para todos, o que representa, segundo BRAUNACK \& DEXTER (1989), o tamanho adequado de agregados para o bom desenvolvimento e produção de várias culturas.

Comparando-se os valores relativos a cada um dos tratamentos, verifica-se que a classificação da percentagem média acumulada de agregados, por classe de tamanho, apresenta ordem decrescente para quase todas as classes: arado de aivecas $<$ escarificador $<$ arado de discos $<$ grade aradora $<$ enxada rotativa (Figura 2 ). 


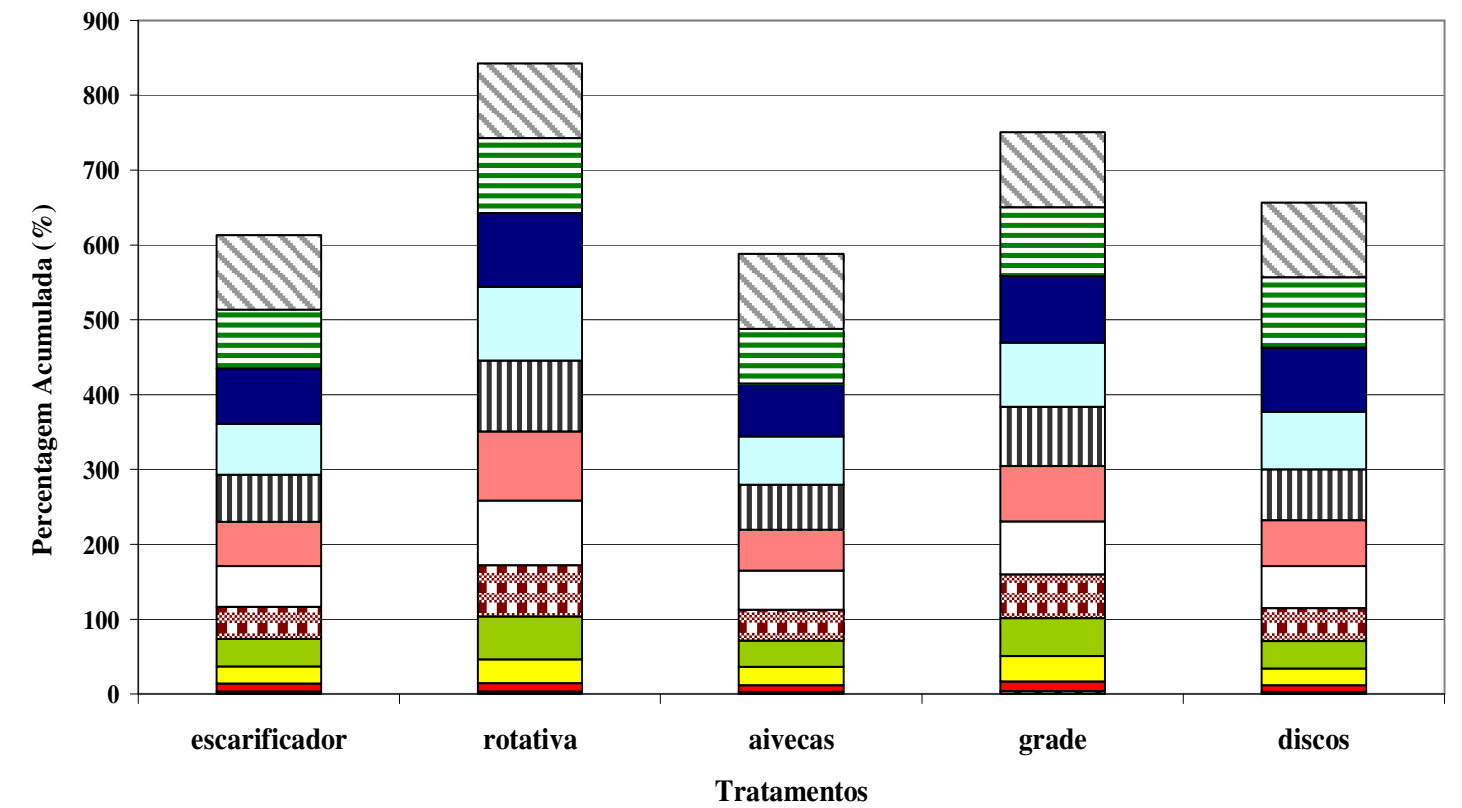

\begin{tabular}{|lllllll}
\hline$\square 50,800$ & $\square 38,100$ a 50,800 & $\square 25,400$ a 38,100 & $\square 19,000$ a 25,400 & $\square 12,700$ a 19,000 & ⿴囗十 9,520 a $12,700 \quad \square 4,750$ a 9,520 \\
$\square 2,360$ a 4,750 & $\square 1,190$ a 2,360 & $\square 0,590$ a 1,190 & $\square 0,300$ a 0,590 & $\boxminus 0,150$ a 0,300 & $\square<0,150$
\end{tabular}

FIGURA 2. Distribuição percentual acumulada de agregados por classe de tamanho, em função do sistema de preparo periódico do solo.

\section{Diâmetro médio geométrico (DMG) e módulo de finura (MF)}

Na Figura 3, observa-se que o preparo periódico do solo com o arado de aivecas resultou em valores superiores de DMG e MF dos agregados, comparado à enxada rotativa que apresentou os menores valores.

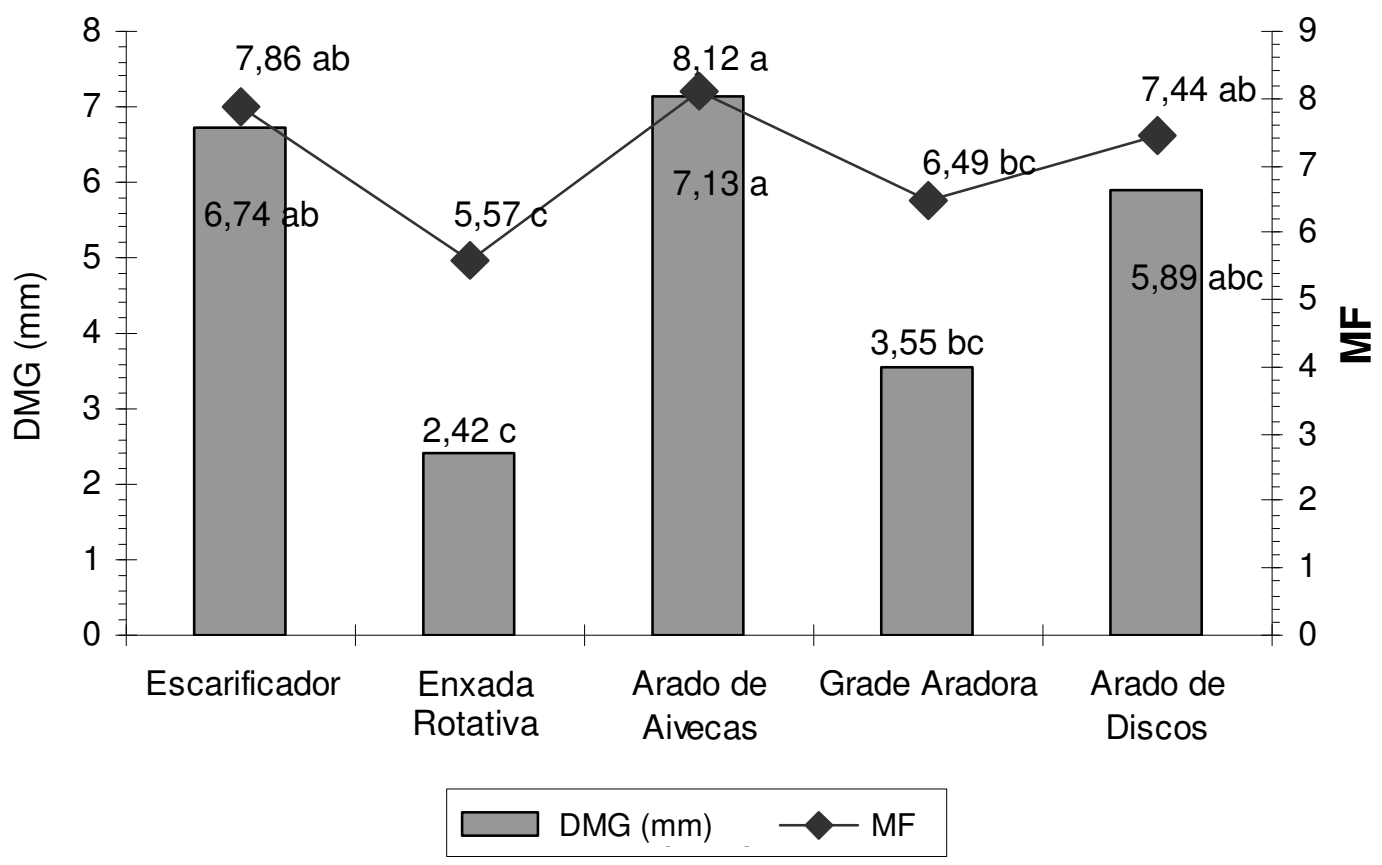

FIGURA 3. Diâmetro médio geométrico (DMG) e módulo de finura (MF) dos agregados, em função dos equipamentos de preparo periódico do solo. 
A existência de agregados maiores atende a um dos requisitos do manejo conservacionista do solo, uma vez que os agregados grandes conferem ao solo maior resistência contra a erosão. Dessa forma, como relatado por BOLLER et al. (1997), o preparo do solo com o escarificador e com o arado de aivecas e de disco atende a essa condição.

BRAUNACK \& DEXTER (1989) sugerem valores de DMG menores que $5 \mathrm{~mm}$ para várias culturas por melhorarem o contato solo-semente. Assim, os tratamentos que melhor atendem tal sugestão são os da grade aradora e da enxada rotativa, entretanto o solo fica mais predisposto à erosão.

COAN (1995) obteve menores valores de DMG e MF dos agregados do solo, além de não observar diferenças significativas entre os tratamentos quando utilizou equipamentos similares, provavelmente porque trabalhou com um Latossolo Vermelho eutroférrico, textura argilosa, que apresenta maior conteúdo de argilas oxídicas, que favorecem a estabilidade estrutural (RESENDE et al., 1995) pela formação de microestrutura mais forte.

\section{Incorporação de resíduos}

Pelos resultados apresentados na Figura 4, observa-se que, antes da instalação do trabalho, a área experimental apresentava distribuição uniforme de resíduos sobre o solo.

Após o preparo primário, constatou-se que os diferentes sistemas de preparo apresentaram capacidades de incorporação distintas estatisticamente. Nota-se que o escarificador e a enxadarotativa incorporaram $28,4 \%$ e $58,8 \%$ da cobertura existente sobre o terreno, respectivamente, o que os confirma como equipamentos apropriados para o sistema de preparo periódico reduzido. FURLANI (2000) chegou a conclusão semelhante ao comparar o preparo convencional com o emprego do arado de discos e o preparo reduzido, com o uso do escarificador.

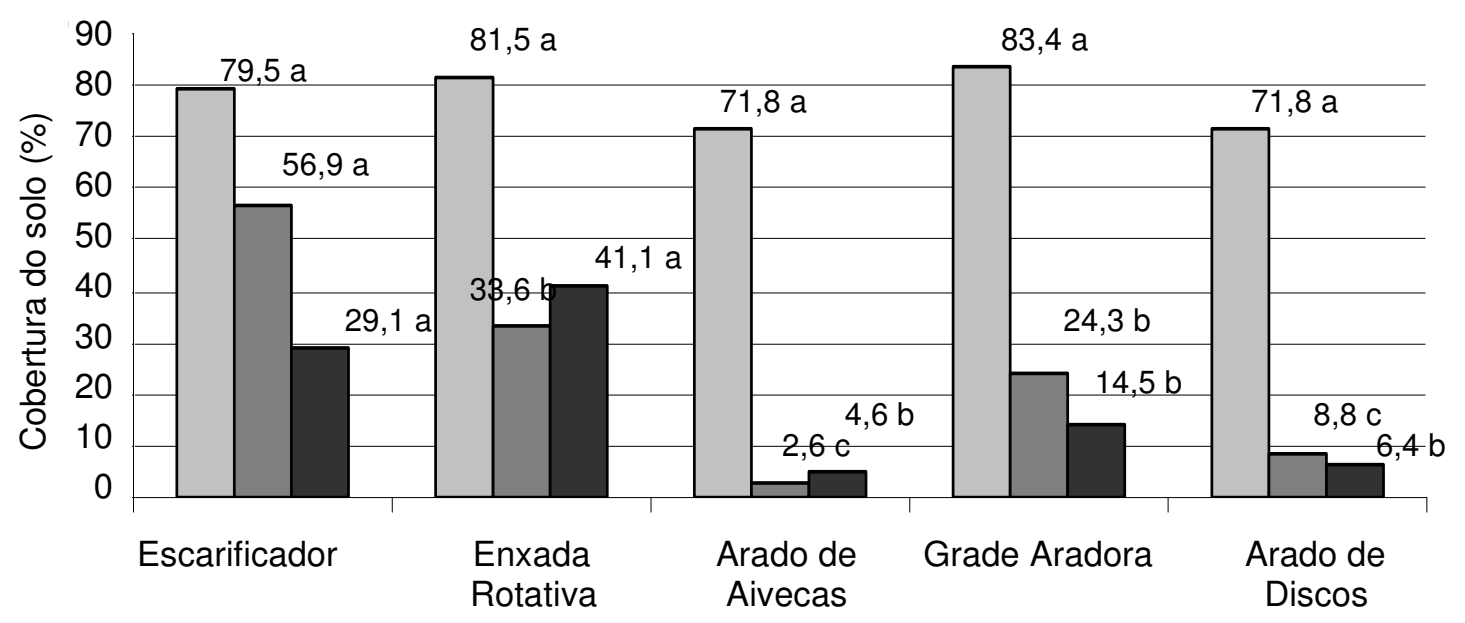

Antes do preparo inicial $\square$ Após o preparo inicial $\square$ Após o preparo secundário

FIGURA 4. Valores médios de cobertura (\%), em função do sistema de preparo periódico do solo.

O emprego da grade aradora também proporcionou baixa capacidade de incorporação, permanecendo $24,3 \%$ de cobertura vegetal sobre o solo, fato também observado por HOOGMOED \& DERPSCH (1985), MARTUCCI (1985), SCHLOSSER et al. (1992), GAMERO \& SILVA (1993) e DALLMEYER (1994).

Os arados tiveram destaque com maior capacidade de incorporação, notadamente o arado de aivecas com $96,4 \%$, deixando o solo com a menor cobertura vegetal na superfície $(2,6 \%)$, comparados aos demais equipamentos. 
Colocando-se em ordem decrescente, quanto à incorporação de resíduos, tem-se: arado de aivecas $(96,4 \%)>$ arado de discos $(87,8 \%)>$ grade aradora $(70,9 \%)>$ enxada rotativa $(58,8 \%)>$ escarificador $(28,4 \%)$. Resultados semelhantes também foram obtidos por COAN (1995).

Após o preparo secundário do solo, os arados, juntamente com a grade aradora, proporcionaram a menor cobertura da superfície do solo pelos resíduos vegetais, justificado pela realização de duas operações com a grade niveladora, enquanto o escarificador realizou apenas uma operação de nivelamento (com grade niveladora) e a enxada rotativa, nenhuma. Outros fatores também corroboraram isso, como o tipo de ferramenta ativa, a profundidade de operação e o trabalho de inversão do prisma de terra.

\section{CONCLUSÕES}

A enxada rotativa e a grade aradora produziram maior percentual de agregados com tamanho adequado para o bom desenvolvimento e produção de várias culturas; entretanto, podem proporcionar maior erosão nos solos, embora possam ser regulados e/ou utilizados para formarem tamanhos de agregados maiores.

Os sistemas de preparo com o escarificador e a enxada rotativa proporcionaram menor incorporação de resíduos vegetais, comparados aos sistemas com arados e com a grade aradora.

A grade aradora proporcionou grande incorporação dos resíduos vegetais e grande quantidade de agregados de pequenas dimensões, podendo gerar maior degradação nos solos.

O preparo do solo com o escarificador atende à condição de manejo conservacionista por proporcionar agregados de maior tamanho e por manter elevada quantidade de resíduos na superfície do solo.

\section{REFERÊNCIAS}

BOLLER, W.; GAMERO, C.A.; PEREIRA, J.O. Avaliação de diferentes sistemas de preparo e de condições de cobertura do solo. Engenharia Agrícola, Jaboticabal, v.17, n.2, p.52-63, 1997.

BRAUNACK, W.A.; DEXTER, A.R. Soil aggregation in the seedbed: a review. II. Effect of aggregate sizes on plant growth. Soil \& Tillage Research, Amsterdam, v.14, n.3, p.281-98, 1989.

BUHLER, D.D. Influence of tillage systems on weed population dynamics and management in corn and soybean in the central USA. Crop Science, Madison, v.35, n.5, p.1247-58, 1995.

DIAS, C.A.C. Cultura da batata. Campinas: CATI, 1993. 33 p.

COAN, O. Sistemas de preparo de solo: efeitos sobre a camada mobilizada e no comportamento das culturas do feijoeiro (Phaseolus vulgaris L.) e do milho (Zea mays L.), conduzidas em rotação. 1995. 138 f. Tese (Livre-Docência) - Faculdade de Ciências Agrárias e Veterinárias, Universidade Estadual Paulista, Jaboticabal, 1995.

DALLMEYER, A.U. Eficiência energética e operacional de equipamentos conjugados de preparo de solo. 1994. 157 f. Tese (Doutorado em Energia na Agricultura) - Faculdade de Ciências Agronômicas, Universidade Estadual Paulista, Botucatu, 1994.

DICKEY, E.C.; SIEMENS, J.C.; JASA, P.J.; HOFMAN, V.L.; SHELTON, D.P. Tillage system definitions. In: _. Conservation tillage systems and management: crop residue management with no-till, ridge-till, mulch-till. Ames: Midwest Plan Service, 1992. p. 5-7.

FURLANI, C.E.A. Efeito do preparo do solo e do manejo da cobertura de inverno na cultura do feijoeiro (Phaseolus vulgaris L.). 2000. 218 f. Tese (Doutorado em Energia na Agricultura) Faculdade de Ciências Agronômicas, Universidade Estadual Paulista, Botucatu, 2000.

GAMERO, C.A. Desagregação do solo em diferentes métodos de preparo. In: CONGRESSO BRASILEIRO DE ENGENHARIA AGRÍCOLA, 18., 1989, Recife. Anais... Jaboticabal: Sociedade Brasileira de Engenharia Agrícola, 1989. p.254-67. 
GAMERO, C.A.; SILVA, J.G. Efeitos de ordens de gradagens e de sistemas de aração na camada mobilizada. In: CONGRESSO BRASILEIRO DE ENGENHARIA AGRÍCOLA, 22., 1993, Ilhéus. Anais... Ilhéus: Sociedade Brasileira de Engenharia Agrícola, 1993. p.1536-53.

GROHMANN, F.; ARRUDA, H.V. Influência do preparo do solo sobre a estrutura da Terra Roxa Legítima. Bragantia, Campinas, v.20, n. 2, p.1203-9, 1961.

GUPTA, S.C.; LARSON, W.E. Modeling soil mechanical behavior during tillage. In: AMERICAN SOCIETY OF AGRONOMY. Predicting tillage effects on soil physical properties and processes. Madison: Soil Science Society of America, 1982. p.151-78.

HOOGMOED, W.B.; DERPSCH, R. Chisel ploughing as an alternative tillage system in Paraná, Brazil. Soil and Tillage Research, Amsterdam, v.6, n.1, p.53-67, 1985.

LAFLEN, J.M.; AMEMIYA, M.; HINTZ, E.A. Measuring crop residue cover. Journal of Soil Water Conservation, Ankeny, v.36, n.6, p.341-3, 1981.

LEVIEN, R.; GAMERO, C.A.; FURLANI, C.E.A. Preparo convencional e reduzido em solo argiloso em diferentes condições de cobertura de inverno. Engenharia Agrícola, Jaboticabal, v.23, n.2, p.277-89, 2003.

LOPES, R.A.P. Monitoramento de propriedades físicas do solo sob dois sistemas de preparo na sucessão soja-milho no período de três anos. 2002. 73 f. Dissertação (Mestrado em Engenharia de Sistemas Agroindustriais) - Universidade Estadual do Oeste do Paraná, Cascavel, 2002.

MARTUCCI, F.C. Escarificador no preparo do solo. A Granja, Porto Alegre, v.16, n.6, p.44-6, 1985.

MAZUCHOWSKI, J.Z.; DERPSCH, R. Guia de preparo do solo para culturas anuais mecanizadas. Curitiba: ACARPA, 1984. 68 p.

MORAES, M.H.; BENEZ, S.H. Efeitos de diferentes sistemas de preparo do solo em algumas propriedades físicas de uma Terra Roxa Estruturada e na produção de milho para um ano de cultivo. Engenharia Agrícola, Jaboticabal, v.16, n.2, p.31-41, 1996.

RESENDE, M.; CURI, N., REZENDE, S.B. de; CORRÊA, G.F. Pedologia: base para distinção de ambientes. Viçosa: NEPUT, 1995. 304 p.

SALVADOR, N.; BENEZ, S.H.; BICUDO, S.J. Preparo periódico do solo I: desempenho operacional e mobilização do solo. In: CONGRESSO BRASILEIRO DE ENGENHARIA AGRÍCOLA, 22., 1993, Ilhéus. Anais... Ilhéus: Sociedade Brasileira de Engenharia Agrícola, 1993. v.3, p.1710-20.

SCHLOSSER, J.F.; SILVEIRA, D.R. da; KOCHHANN, M.R.; CARGNELUTTI FILHO, A. Preparo do solo para o arroz (Oriza sativa L.) irrigado: desempenho operacional dos implementos. In: CONGRESSO BRASILEIRO DE ENGENHARIA AGRÍCOLA, 21., 1992, Santa Maria. Anais... Santa Maria: Sociedade Brasileira de Engenharia Agrícola, 1992. v.3, p.1521-33. 